\title{
Ethnic-Racial Socialization as an External Predictor of Tolerance for Diversity: A Study of Chinese-Indonesian Young Adults
}

\section{Levina Xaveria ${ }^{\mathrm{a}}$ and Sri Redatin Retno Pudjiati ${ }^{\mathrm{b}}$}

${ }^{a}$ Faculty of Psychology, Universitas Indonesia, Depok, Indonesia; ${ }^{b}$ Department of Developmental Psychology, Faculty of Psychology, Universitas Indonesia, Depok, Indonesia

*Corresponding author:

Sri Redatin Retno Pudjiati

Department of Developmental Psychology, Faculty of Psychology, Universitas Indonesia Jl. Lkr. Kampus Raya, Depok, Jawa Barat Indonesia, 16424

Tel.: +62 217270004

Email address: retno-pj@ui.ac.id 


\title{
Ethnic-Racial Socialization as an External Predictor of Tolerance to Diversity: A Study of Chinese-Indonesian Young Adults
}

\begin{abstract}
The Chinese-Indonesian ethnic minority is one of the minorities in Indonesia with a long time history of being treated differently, for example the Kerusuhan 1998 (the 1998 riot). Because of this riot, this ethnic minority experienced trauma, held negative stereotypes against the majority, and now tend to avoid any unnecessary contact with the ethnic majority, causing a lower level of tolerance to the ethnic majority. Therefore, a study about tolerance in this ethnic minority is important, to increase better ethnic interaction between the minority and majority ethnicities. Previous studies have found the role of personal factors (i.e... empathy and personality) to influence the development of tolerance to diversity. This study is looking for another possibility in terms of external factors that can influence tolerance to diversity, since tolerance is something that can be taught and learnt. The one possibility is ethnic-racial socialization from parents. Therefore, this study looks the relationship between tolerance to diversity and ethnic-racial socialization in Chinese-Indonesian young adults $(N=208$, age 19 - 30 years old $)$; the age range, which has the strongest relationship for tolerance to diversity. Results showed a negative relationship of ethnic-racial socialization and tolerance. This finding suggests that perhaps the discrimination that they already experienced before could contribute something on the process of socialization. Future studies about ethnicracial socialization are still needed to analyze on how parents of ChineseIndonesians develop their children's tolerance to diversity.
\end{abstract}

Keywords: tolerance to diversity, Chinese-Indonesian, young adults, ethnic-racial socialization, external factors

\section{Introduction}

Indonesia is the fourth most populated country in the world, with around an estimated 260,580,739 people by July 2017 (Central Intelligence Agency, 2017), with some diverse ethnicities and cultures. There are two main ethnic majorities in Indonesia, the Javanese $(40.1 \%)$ and Sundanese (15.5\%). Some of the smaller ethnic minorities in Indonesia are Banjarnese and Balinese (1.7\%), Acehnese and Dayaknese (1.4\%), and also the Sasaknese and Chinese-Indonesian (1.2\%).

With such a diverse ethnicities and religions, the probability of conflicts arising between majority and minority are more pronounced. Chinese-Indonesian is one of the ethnic minorities in Indonesia who had a long time experience of being treated differently. During the Dutch colonial period, Indonesian society was divided into three classes: (1) European (usually dominated by the Dutch), (2) Asian (usually dominated by foreigners from China), and (3) Pribumi (or the local Indonesian people) (Suryadinata, 2003).

This separation of classes in Indonesian society then continued during Order Baru (New Order) under the leadership of President Soeharto. At that time, the Chinese descendant people, who were actually already born in Indonesia, were still considered to be Warga 
Negara Asing (foreign citizens) (Suryadinata, 2003). Therefore, President Soeharto came up with an idea to assimilate the Chinese already born in Indonesia (so-called ChineseIndonesian in the era of President Soekarno) with the locals. For example, he imposed limits on the number of Mandarin newspapers, and also the organization and schools formed by the Chinese-Indonesians. During the New Order regime, Chinese-Indonesians were also asked to change their Chinese names to local names (Suryadinata, 2003). The government also limited their occupational field to business and trading.

Unfortunately, these policies were considered a failure in terms of making the ChineseIndonesian minority assimilate with the local people (Hoon, 2006). First, even though the Chinese-Indonesians were de facto already assimilated, the local Indonesians still considered them as foreigners, because they had foreign antecedents (Hoon, 2006). Second, due to higher economic power compared to the locals, the Chinese-Indonesians had the tendency to consider themselves of higher status than local Indonesians, which led to the emergence of a negative stereotype toward the local Indonesians, who were considered lazy and often made use of their higher economic power. Later, this negative stereotype also led to prejudice from the Chinese-Indonesian minority toward the locals (Hoon, 2006).

The peak of this negative ethnic interaction then leads to "Kerusuhan 1998" (the 1998 riot) in Jakarta, which was reported to be based on negativity towards the Chinese-Indonesian ethnic minority (Suryadinata, 2003). Because of this riot, around 1.5\% Chinese-Indonesians fled Indonesia and moved to other countries, and some of them decided not to return to Indonesia, because of their traumatic experience (Suryadinata, 2003). This traumatic experience, whether they experienced it directly or indirectly, later contributed more to their negative stereotype of local Indonesians, which led to the reluctance of Chinese-Indonesians to interact with the locals, automatically lowering their tolerance level of the local Indonesians.

Tolerance, described by the term "universal-diverse orientation" or UDO is a positive attitude toward others, including awareness of universality, and also an openness to embrace diversity (Miville, Romans, Johnson \& Lone, 2004). Previous studies already found some personal predictors that influence the development of tolerance, i.e. empathy (empathic concern) and personality (Openness and Agreeableness) (Butrus \& Witenberg, 2012; Gerson \& Neilson, 2014).

The other personal factor is psychosocial development of the "intimacy vs isolation" stage. A previous study stated that young adults are the stage where they can have more opportunities to interact with more diverse individuals compared with the other life stages (Gerson \& Neilson, 2014). These interactions then lead the person to have a higher interest in others that come from different backgrounds, for example others with different ethnicities.

However, there are some possibilities that tolerance can also can be predicted by external factors; because the theory stated that tolerance is something that can be taught and learned especially if the person is supported by certain circumstances (Butrus \& Witenberg, 2012; Gerson \& Neilson, 2014). One possibility is the influence exercised by parents on children. 
Degner and Dalege (Degner \& Dalege, 2013) on their meta-analysis study stated that the connection between parents' and children's intergroup attitudes is determined by socialization. But there are no previous studies that stated how the socialization happened. Therefore, the current study took the term "ethnic-racial socialization" to explain how the socialization process actioned parents could contribute to the tolerance level of their young adult children.

Ethnic-racial socialization is the transmission of information, values, and perspectives about ethnicity and race from parents to their children (Hughes, Rodriguez, Smith, Johnson, Stevenson, \& Spice, 2006). This socialization is usually done by ethnic minority parents to help their children to function well in a society, which otherwise tends to devalue their ethnic status (White-Johnson, Ford \& Sellers, 2010).

There are some factors that could influence parents' ethnic-racial socialization: (1) characteristics of the children, such as age; (2) parents' characteristics, such as the parents' ethnic identity and income (Hughes et al., 2006). Previous studies predominantly took the case of African-Americans, an ethnic minority which usually has lower economic status compared to the ethnic majority (Harris-Brit, Valrie, Kurtz-Costes \& Rowley, 2007; WhiteJohnson et al., 2010). Ethnic minority Chinese-Indonesians can be a good sample for the continuity of ethnic-racial socialization studies, because of their unique characteristics. This ethnic minority has greater economic power compared to the ethnic majority, so that this difference should contribute any effect for the socialization process.

In short, the purpose of this study is to look how far is the contribution of ethnic-racial socialization impacts on the development of tolerance in Chinese-Indonesians young adults.

\section{A. Ethnic-Racial Socialization and its Contents}

Ethnic-racial socialization is the transmission of information, values, and perspectives about ethnicity and race from parents to their children. There are four aspects in this socialization, which are: (1) "cultural socialization", (2) "preparation for bias", (3) "promotion of mistrust", and (4) "egalitarianism and silence about race" (Hughes et al., 2006).

"Cultural socialization" is the way parents taught their own children about their own ethnicity. In this content, parents taught the children about specific cultural events and specific values that had been held and taught from generation to generation (Hughes et al., 2006).

"Preparation for bias" is how parents prepare their children to face discrimination and to be ready for being treated differently by the wider society. This practice has been found to be a good protective factor for ethnic minorities, who usually have a tendency to be treated differently by the wider society (Hughes et al., 2006). So, there is coping skill that parents taught to the children in this context. 
On other hand, in the context of "promotion of mistrust", parents are emphasizing the need to avoid much intergroup interaction, especially with people from different ethnic backgrounds. Parents also inculcate a wariness to making a relationship with individuals who come from different ethnic backgrounds, by making the children worried that they could not succeed in the wider society, because they come from an ethnic minority background (Hughes et al., 2006).

Therefore, compared to preparation for bias, in this context parents do not give any positive coping preparation for the children to face discrimination. Rather, parents advised their children to avoid interethnic interaction so that they do not experience discrimination.

The last aspect of ethnic-racial socialization is "egalitarianism". In this content, parents tend to instill universal beliefs and values, and also strengthen the children's personal skills so that they can compete fairly in the wider society, and not be judged by their ethnicities. Some of the beliefs and values that parents usually teach are hard work, equality, virtue, and colorblind perspective (Hughes et al., 2006). So, in this context parents emphasize the importance of personal qualities, rather than prejudgements of their quality based on ethnic background.

\section{B. Positive and Negative Effects of the Content of Ethnic-Racial Socialization}

Previous studies had found the positive impact of ethnic-racial socialization on several psychological aspects, especially in the development of the ethnic minority. For example, previous study already found the positive impact of the context "cultural socialization" from ethnic-racial socialization (Hughes, Witherspoon, Rivas-Drake \& West-Bey, 2009). In this content, parents are implementing ethnic pride and teach children to understand their own traditional practices. The socialization later affects children's self-esteem, and indirectly impacts their children's academic achievement.

Hughes, et al. also found the positive impact in the context of "preparation for bias", which parents prepare and teach their children to have positive coping skills, when they have to face discrimination from society due to their ethnic minority status (Hughes et al., 2006).

However, at the same time, this context has the negative impact as well. Hughes et al. (2009) found a negative relationship between preparation for bias, self-esteem, and the ethnic identity of a child. Harris-Britt et al. (2007) also found the same result, that overexposing "preparation for bias" to the children can increase the feeling of devaluation, which finally affects their self-esteem as well.

The other negative impact of ethnic-cultural socialization is found in the context of "promotion of mistrust", where parents teach their children to not easily trust others, especially someone who comes from a different ethnic background. This component is then found to have negative effect on social competence, as well as being connected with negative acts toward people from different ethnic and racial backgrounds (Tran \& Lee, 2006). Thus, this content is considered as not teaching the children the positive way to overcome 
discrimination, but instead they are inviting the children to think and act negatively toward other people.

With inconsistent results of the effects of each content, therefore it is still worthwhile doing further research on ethnic-racial socialization. The ethnic minority Chinese-Indonesians could be a good example, since ethnic-racial socialization is important for supporting the ethnic minority in facing discrimination acts from the majority.

\section{Methods}

\section{A. Participants}

The sample of this study comprised 208 participants, aged between 19 and 30 years, with the majority of being 26-30 (48.6\%); while other age ranges were 19-21 (20.7\%), and 22-25 $(30.8 \%)$.

Most of the participants were women, of a total of 134 participants (64.4\%), with only 74 men $(35.6 \%)$. Of the total participants, $75 \%$ were of pure Chinese descent, which means both parents were Chinese-Indonesian; and $25 \%$ were of half Chinese descent, which means only one parent had a Chinese-Indonesian background. Participants mostly had a bachelor's degree $(69.7 \%)$ or were still studying in high school $(15.9 \%)$.

The background education of most fathers of participants was as high school graduates $(n=$ $92 ; 44.2 \%)$, followed by undergraduates $(n=55 ; 26.4 \%)$. Most of the mothers were also high school graduates $(n=102 ; 49 \%)$, followed by undergraduates $(n=51 ; 24.5 \%)$.

Most of the participants also came from a family whose income was below IDR $112,000,000$ per year $(n=94,45.2 \%)$; followed by participants who reported their parents' income above IDR $127,000,000$ per year $(n=74,35.6 \%)$.

\section{B. Procedure}

Universitas Indonesia's Faculty of Psychology ethic committee already approves this study for research with human participants. Participants in this study were recruited online, by completing the questionnaire that had been made in Google Form. The questionnaire pack contained an informed consent, the personal data of the participants, and the measurement instruments to measure tolerance, ethnic-racial socialization, and other two independent variables of the study, which are ethnocultural empathy and personality. The Google Form link was distributed via chatting apps and social media. Participants were then compensated for the time they had spent completing the questionnaires.

At the beginning of the questionnaire, participants were adivesd on the details of the research's aim, procedures, and participants' criteria. Participants were also informed that they had the right to withdraw from the study, because participation was voluntary. Participants were also assured that their personal information would be kept confidential, and only used for this research and academic purposes only. Participants were given contact 
number and email address of the researcher, in case they had any further questions or concerns.

\section{Measurements}

1) Demographic. Information was requested regarding the demographic status of the participants including age, gender, ethnicity, and socioeconomic status (SES), such as background education, work field, and income (if any), as it was already stated before how SES status may have influence on ethnic-racial socialization (Hughes et al., 2006). Detailed ethnicities of both parents and also their SES status (i.e., background education and income) were also included in the questionnaire, as previous study already stated that these factors could influence how parents exercise ethnic-racial socialization with their children (Hughes et al., 2006).

2) Tolerance. Tolerance is described as universal-diversity orientation (UDO); a positive attitude to others, including awareness and openness toward ethnic or racial differences, which was measured by Miville-Guzman Universality-Diversity Scale Short Form / MGUDS-S (Fuertes et al., 2000). The initial instrument, the M-GUDS (Fuertes, Miville, Morh, Sedalcek, \& Gretchen, 2000) consists of 45 items, rated on 6-point scales $(1=$ strongly disagree, $6=$ strongly agree). But the short form that only consists of 15 items, still has item's inter-correlate as good as the longer form.

There are three factors on the scale, which are: (1) diversity contact, which describes the behavior component of UDO; (2) relativistic appreciation, which describes the cognitive component of UDO; and (3) comfort with difference, which describes the affective component of UDO.

Diversity contact described an interest of an individual to interact with diverse cultures and diverse ethnicities. For example, joining an organization, attending an event, or learning about another culture and tradition of different ethnicities.

Relativistic appreciation described how an individual appreciates similarities and differences with other people. Meanwhile, comfort with differences described how an individual not only has a feeling of connectedness with other people, but also how he/she feels comfortable when dealing with differences.

Based on a pilot study of 40 individuals, the Pearson correlation for this instrument is between 0.207 and 0.626 . The reliability coefficient for this instrument is 0.662 , which was considered acceptable (Hair Jr., et al.,2010).

3) Ethnic-Racial Socialization. Ethnic-racial socialization is the transmission of information from parents to their children regarding race and ethnicity, specifically Chinese-Indonesian ethnicity. This socialization is measured by Asian-American Parental Racial-Ethnic Socialization Scales / AAPRESS (Juang et al., 2016). This instrument includes 61 items, with 
Cronbach Alpha 0.901, which was considered as excellent (Hair Jr., Black, Babin \& Anderson, 2010).

This instrument was initially started with a sentence "One way we learn about culture and ethnicity is through our parents. Please indicate if one or more of your parents have engaged in each of the following activities, and if so, how frequently" (Juang et al., 2016), and be rated on 5 -point scales $(1=$ never, to $5=$ very often $)$.

The scale is divided into seven subscales. The initial seven subscales are: (a) maintenance of heritage culture, (b) becoming American, (c) awareness of discrimination, (d) avoidance of outgroups, (e) minimization of race, (f) promotion of equality, and (g) cultural pluralism. Later, the dimension "becoming American" is translated into "becoming Indonesian", to match the cultural context of Chinese-Indonesians. And the total of 61 items will be fully used for the analysis, especially to test this instrument on different samples in different geographical territories, which are Chinese-Indonesian, but roughly has some similarities with the sample used in the original study.

Maintenance of heritage culture is the way parents teach their children to maintain culture and tradition of their own ethnicity. Becoming American denotes the way parents teach their children to blend with the American culture. Awareness of discrimination is how parents instill awareness to their children about discrimination acts that they will experience because of their ethnic minority status.

Avoidance of outgroups is how parents teach children to avoid certain people with different race or ethnicity background and to avoid their cultural celebration. Minimization of race is the way parents try to prevent racism in their children by considering that ethnic background is not important. Promotion of equality is how parents teach children to treat everyone fairly even though they come from different ethnic backgrounds. Cultural pluralism is how parents teach children to appreciate culture from different ethnicities and races by educating them about different cultures.

\section{Results}

The means and standard deviation for all dimensions or factors of the instruments are presented below in Table I. 
Table I. Means and Standard Deviation for All Dimensions or Factors $(N=208)$

$\begin{array}{clcc}\text { Instruments } & \text { Dimensions / Factors } & \text { Mean } & \text { SD } \\ \text { M-GUDS-S } & \text { Diversity contact } & 4.8 & 0.79 \\ & \text { Relativistic appreciation } & 4.9 & 0.64 \\ & \text { Comfort with differences } & 4.47 & 0.79 \\ & & & \\ \text { AAPRESS } & \text { Maintenance of heritage } & 2.82 & 0.72 \\ & \text { culture } & 4.13 & 0.69 \\ & \text { Becoming Indonesian } & 3 & 0.89 \\ & \text { Awareness of discrimination } & 2 & 0.81 \\ & \text { Avoidance of outgroups } & 2.28 & 1 \\ & \text { Minimization of race } & 3.95 & 0.9 \\ & \text { Promotion of equality } & 3.29 & 0.94 \\ \text { Cultural pluralism } & & \end{array}$

Simple multiple regression was conducted to see the relation of ethnic-racial socialization ( $M$ $=2.96, \mathrm{SD}=0.44)$ and tolerance to diversity $(M=4.71, \mathrm{SD}=0.55)$. Correlation of the two variables is tested with Pearson correlation $(r=0.367)$. Result shows that the relation of both variables is negatively significant $(\beta=-0,3 ; \mathrm{t}(207)=-3,66)$.

There is also no significant relationship between ethnic-racial socialization and fathers' background education $(r=-0.12)$, as well as mothers' background education $(r=-0.13)$. This study also found no relationship between ethnic-racial socialization and parents' income ( $r=$ $-0.07)$.

\section{Discussion}

The result of this study showed significant relationship between tolerance to diversity and ethnic-racial socialization in a negative way. This is not as hypothesized because previous studies predominantly found ethnic-racial socialization to be a protective factor to help ethnic minority children survive in discriminative society. This unexpected result is perhaps connected to which context or dimension in the ethnic-racial socialization that predominantly taught by the Chinese-Indonesian parents.

In this study, the result showed that in Chinese-Indonesians, the dimension of "promotion to equality" has the biggest coefficient compared to other dimensions in ethnic-racial socialization. The dimension of "promotion of equality" is a dimension in which parents emphasize the equality of every people, irrespective of ethnicity. This dimension would be closely connected to the content of "egalitarianism", where parents choose to place more emphasis on universal values and help their children to develop personal characteristics so that they can compete fairly in society.

Nevertheless, in the Chinese-Indonesian sample, the dimension of "promotion to equality" was found to have a negative contribution to ethnic-racial socialization. Therefore, it can be concluded that parents of Chinese-Indonesian children emphasize this "egalitarianism" content negatively, which means they do not lay emphasis on their children's personal 
characteristics, but emphasize more how their minority status influences their actions in the society.

A previous literature study by Hughes et al. (2006) found some factors that could influence the frequency of ethnic-racial socialization content taught by the parents. The first one is socioeconomic status, which is represented by parents' background education and income in this study. Unfortunately, data analysis of this study found that there are no significant effects of both socioeconomic statuses to ethnic-racial socialization.

The second factor that could influence how parents socialize about ethnicity and race is the living area and how they had experienced discrimination. A previous study found that an ethnic minority who lived in a multicultural place, or lived in the area that had a negative social climate because of previous discrimination acts, tended to socialize more in the context of "preparation for bias" and "egalitarianism" (Hughes et al., 2006). Nevertheless, because the riot of 1998 had some traumatic effects on the Chinese-Indonesians (Suryadinata, 2003), and they did not want the children to experience the same. Therefore, it could be the reason why the Chinese-Indonesian parents taught "egalitarianism" negatively.

The other factor that could affect Chinese-Indonesian parents' socialization could be their ethnic-identity. A previous study found that if parents have stronger ethnic identity, they tend to teach their children more about their own tradition, culture, ideology, and knowledge about their own ethnicity or race (Hughes et al., 2006), which could lead to higher self-esteem in their children. However, previous study found that older generations of Chinese-Indonesians tend to lay more emphasis on "being" Chinese rather than "becoming" and blending with Indonesian culture (Christian, 2017). Therefore, it also can contribute to how the ChineseIndonesians viewed themselves compared to the ethnic majority.

\section{Strengths and Limitations}

This study specifically would be the first study that seeks to analyze how ethnic-racial socialization can be one of the external factors that influence tolerance. This is also the first study in the Indonesian context about the factors that contribute to tolerance development. This study may also be the first study that took Chinese-Indonesian ethnic minority as the sample of study, because this ethnic minority has higher economic power, which is different from the ethnic-minority cohort from the previous studies about ethnic-racial socialization.

Limitations of this study would be further studies must pay more attention where the Chinese-Indonesians lived. One study stated that the Chinese-Indonesians people who live in the city of Medan, Pontianak, Singkawang, and Kepulauan Bangka-Belitung, tend to maintain a stronger Chinese culture (Christian, 2017). Therefore, this factor could affect the ethnic-racial socialization, because these Chinese-Indonesians might have different ways to interact with the majority. 
Another limitation of this study would be how the researcher looks ethnic-racial socialization as having a direct relationship with tolerance, rather than considering that there might be any mediator between them. Previous studies already found that self-esteem and ethnic identity are the mediators between ethic-racial socialization and academic outcomes of $5^{\text {th }}$ grader students (Hughes et al., 2009).

There might be a chance that something could mediates the relationship between ethnic-racial socialization and tolerance, since this study found the negative relationship between both of the variables. For example, future studies on Chinese-Indonesian young adults could see how the interaction with the diverse environment might also influence their parents' socialization, as the newest research from Miklikowska (2017) stated that, in a longitudinal study, adolescents who have more intergroup friendships are less affected by parents' prejudicial attitudes.

\section{Conclusion}

A previous study already found that the development of tolerance is influenced by personal factors, such as empathy and personality. This study analyzes the other external factors that might influence the development of tolerance as well. Results from this study found that tolerance is specifically influenced by ethnic-racial socialization that the children received from their parents during their childhood.

Nevertheless, the relationship between tolerance and ethnic-racial socialization is found to be negative. Specifically, in Chinese-Indonesian young adults, the result found that the dimension of "promotion of equality", which will be connected to the content of "egalitarianism", was also found to have negative coefficient. That means, rather than to emphasize more on the children's personal characteristics in the socialization practice, the Chinese-Indonesian parents tend to emphasize how their children's ethnic characteristics would influence every aspect of their life, such as their action towards the ethnic majority.

This result perhaps can be explained by the previous discrimination experienced by the parents, and how parents' ethnic identity could influence socialization in a negative way. Further studies could explore the relationship between these two variables in different Chinese-Indonesian sub-ethnics live in different regions in Indonesia and have stronger culture maintenance than this present study.

Future studies about ethnic-racial socialization on this ethnic minority are still needed, so that the contents of socialization that are taught by Chinese-Indonesian parents can be fully described. This will help the future Chinese-Indonesian parents to apply more positive emphasis on their socialization. So that the children's tolerance will be better in the future, to create a better ethnic interaction with the ethnic majority. 


\section{References}

Butrus, N. \& Witenberg, R. T. (2012). Some personality predictors of tolerance to human diversity: The roles of openness, agreeableness, and empathy. Australian Psychologist, 48, 290-298.

Castelli, L., Zogmaister, C., \& Tomelleri, S. (2009). The transmission of racial attitudes within the family. Developmental Psychology, 45(2), 586-591.

Central Intelligence Agency. (2017). The world factbook, Central Intelligence Agency. Retrieved from https://www.cia.gov/library/publications/the-world-factbook/geos/id.html

Christian, A. S. (2017). Identitas budaya orang Tionghoa Indonesia. Jurnal Cakrawala Mandarin. 1(1), 11-22.

Degner, J. \& Dalege, J. (2013). The apple does not fall far from the tree, or does it? A meta-analysis of parentchild similarity in intergroup attitudes. Psychological Bulletin, 139(6), 1270-1304.

Fuertes, J. N., Miville, M. L., Mohr, J. J., Sedlacek, W. E. \& Gretchen, D. (2000). Factor structure and shortform of the Miville-Guzman Universality-Diversity Scale. Measurement and Evaluation in Counseling and Development, 46(3), 29-307.

Gerson, M. W. \& Neilson, L. (2014). The importance of identity development, principled moral reasoning, and empathy as predictors of openness to diversity in emerging adults. SAGE Open, 4, 1-11.

Giblin, S. (2003). Civil society groups overcoming strereotypes? Chinese Indonesian civil society groups in Post-Suharto Indonesia. Asian Ethnicity, 4(3), 353-368.

Hair Jr., J. F., Black, W. C., Babin, B. J. \& Anderson, R. E. (2010). Multivariate data analysis: A global perspective ( $7^{\text {th }}$ ed.). Saddle River, NI: Pearson Education.

Harris-Britt, A., Valrie, C. R., Kurtz-Costes, B. \& Rowley, S. J. (2007). Perceived racial discrimination and selfesteem in African American youth: Racial socialization as a protective factor. Journal of Research on Adolescence, 17(4), 669-682.

Hoon, C. Y. (2006). Assimilation, multiculturalism, hybridity: The dilemmas of the ethnic Chinese in postSuharto Indonesia. Asian Ethnicity, 7(2), 146-166.

Hughes, D., Rodriguez, J., Smith, E. P., Johnson, D. J., Stevenson, H. C. \& Spicer, P. (2006). Parents' ethnicracial socialization practices: A review of research and directions for future study. Developmental Psychology, 42(5), 747-770

Hughes, D., Witherspoon, D., Rivas-Drake, D. \& West-Bey, N. (2009). Received ethnic-racial socialization messages and youths' academic and behavioral outcomes: Examining the mediating role of ethnic identity and self-esteem. Cultural Diversity and Ethnic Minority Psychology, 15(2), 112-124.

Juang, L. P., Shen, Y., Kim, S. Y., \& Wang, Y. (2016). Development of an Asian American parental racialethnic socialization scale. Cultural Diversity and Ethnic Minority Psychology, 22(3), 417-431.

Miklikowska, M. (2015). Like parent, like child?: Development of prejudice and tolerance towards immigrants. British Journal of Psychology, 107(1), 95-116.

Miklikowska, M. (2017). Development of anti-immigrant attitudes in adolescence: The role of parents, peers, intergroup friendships, and empathy. British Journal of Psychology, 108(3), 626-648.

Miville, M. L., Gelso, C.J., Pannu, R., Liu, W., Touradji, P., Holloway, P., \& Fuertes, J. (1999). Appreciating similarities and valuing differences: The Miville-Guzman universality-diversity scale. Journal of Counseling Psychology, 46(3), 291.

Miville, M. L., Romans, J. S., Johnson, D. \& Lone, R. (2004). Universal-diverse orientation: Linking social attitudes with wellness. Journal of College Student Psychotherapy, 19(2), 61-79.

Tran, A. G. \& Lee, R. M. (2010). Perceived ethnic-racial socialization, ethnic identity, and social competence among Asian American late adolescents. Cultural Diversity and Ethnic Minority Psychology, 16(2), 169-178.

White-Johnson, R. L., Ford, K. R. \& Sellers, R. M. (2010). Parental racial socialization profiles: Association with demographic factors, racial discrimination, childhood socialization, and racial identity. Cultural Diversity and Ethnic Minority Psychology, 16(2), 237.

Suryadinata, L. (2003). Kebijakan Negara Indonesia terhadap Etnik Tionghoa: Dari asimilasi ke multikulturalisme? Antropologi Indonesia, 71, 1-12. 